\title{
Looking into Future - Systems Engineering of Microsatellites
}

\author{
H. Bonyan \\ Faculty of Energy Engineering and New Technologies, Shahid Beheshti University (SBU)
}

Iran

\section{Introduction}

Space age began with the launch of Sputnik-1 in 1957, by the Soviet Union. Initially, the spacecraft, especially the western ones, were rather small due to limited capabilities of the launch vehicles. With the increasing capabilities of rocketry in the US and USSR, the limitation was soon a part of history. From 1970s, several-thousands-kilograms satellites have been placed in orbits ranging from LEOs to GEOs and to interplanetary orbits. These large satellites have been the major payloads of launch vehicles until the very last years of the Cold War, the so-called "Super-power, government-only space era". During the last two decades, however, there has been an ever-increasing interest within the private sectors in developed countries and, also, space agencies of developing countries to contribute to and take advantage of space market. It must be reminded that large satellites are not appropriate means to establish the required hardware-/software-expertise and infrastructure. Simply, the private sector is not able to afford the huge costs of large satellites and its immense complexity. This also holds true for government-funded project in many developing and third-world countries. Thus, most countries and space agencies have adopted microsatellite projects in order to initialize their space policy in order to obtain, establish and benefit from the rich space revenue. Thus, a "government/private-sector era" has been already initiated and almost established. In this methodology, microsatellites have served as "path-finders", in order to pave the way of many nations and societies (top-class universities in developed countries, space-agencies in developing countries and so on) to obtain the space technology. In the space literature of the last two decades, microsatellites have been addressed as "hands-on experience" to facilitate consolidation of space technology in order to implement some "actual large satellite" programs. Microsatellites in the next decades, however, will be employed not only as "path-finders" and/or "hands-on experience" warm-ups, but also as actual projects with considerable financial Return on Investment (ROI). This requires fundamental reconsideration of system-level characteristics of microsatellite projects, such as mission definition, subsystem performance requirements, construction, test, launch and post-launch operations. The preceding issues are addressed in this chapter.

\section{Mission definition}

Traditionally, microsatellites have served as engineering programs in order to pave the way for different communities (universities, organizations and/or nations) to acquire enough

Source: Aerospace Technologies Advancements, Book edited by: Dr. Thawar T. Arif,

ISBN 978-953-7619-96-1, pp. 492, January 2010, INTECH, Croatia, downloaded from SCIYO.COM 
"hands-on experience" for establishment of actual several-hundred/several-thousand kilograms satellite programs. While this approach has considerably contributed to recent advancements in satellite technologies in many developing countries and elsewhere, it still utilizes few of enormous capabilities of microsatellites. Microsatellites developed in the said paradigm, mainly serve to educate highly-qualified space engineers and managers. However, once in orbit, these vehicles are utilized to an order of magnitude less than their full capability. There are evidences that some well-designed, built and launched microsatellites have been almost abandoned after a few months in orbit. However, if properly planned, these vehicles could have been actively in service for a few years rather than a few months. It must be reminded that the owner authorities of the satellites (mostly universities and space-industry) are reluctant to officially declare the ineffectiveness of the actual products of the spaceborne system i.e. microsatellite in orbit and mostly emphasize on educational achievements of such programs. However, according to [H.Bonyan, 2010]; [E.Gill et al., 2008]; [U.Renner \& M.Buhl, 2008]; [G.Grillmayer et al., 2003] \& [United Nations UNISPACE III, 1998], there are evidences that there will be an enormous enhancement in actual outcomes of microsatellite programs, from a practical-application and/or economicalvalue point of view. The enormous enhancement of products of microsatellite programs, stated above, is briefly described in the following paragraphs.

During the last two decades, there has been an immense progress in the miniaturization of equipments incorporated in microsatellite technology. Miniaturization, in its broadest sense, is interpreted as provision of the same level of functionality via fewer resources. In satellite technology, resources are considered as mass, power and volume ${ }^{1}$. Today, with the increasing progress in computer technology, Commercial-Off-The-Shelf (COTS) units are accessible within the commercial space market. While these units are provided at fairly reasonable prices, they are as capable as their quite-expensive predecessors. For a given level of performance, these new units are also lighter and less power-hungry which, in turn, can be considered as extra financial benefit. Also, more efficient solar cells and battery units are now offered by suppliers of various communities. Furthermore, compact, light-weight and reliable reaction wheels and other attitude control actuators are provided by several suppliers [SSTL website, as of 2009]; [Sun Space website, as of 2009]; [Dynacon Inc. website, as of 2009] \& [Rockwell Collins Deutschland website, as of 2009]. A complete list of these new components is not within the scope of this writing. It is being concluded that, at present and near future, microsatellites are and will be capable of fulfilling sophisticated missions, previously feasible only by several-hundred kilogram satellites.

The preceding advancements, to some extent, are true for every engineering field. However, they are an order of magnitude more important regarding microsatellite technology. It is being reminded that mass and power are critical issues in space technology. At the present time (as of 2009), placing a kilogram of payload into Low Earth Orbit (LEO) can be as expensive as 5000-15000 US \$ [Malekan \& Bonyan, 2010]; [Futron Corporation Manual, 2002]. Consequently, there is an ever-increasing interest within the satellite design community to provide the same level of functionality via lighter equipments, thus avoiding

${ }^{1}$ From a systems engineering point of view, all the three said items can be translated into dollars. Generally speaking, lighter, less power-hungry and smaller simply means cheaper! 
high launch costs. Also, purchase of solar cells required to generate 1 watt in orbit may be as expensive as 2500-3000 US \$ [Larson \& Wertz, 1992]. The typical prices are given here in order to help the reader realize the desire within the space community to provide the same level of functionality via equipments consuming less power. It is being concluded that any progress within the preceding arenas can be regarded as saving millions of dollars.

Also, equally important, the unique feature of present and potential progress of microsatellite missions lies within the recent pattern of quality assurance developed within the microsatellite design community. Historically, quality programs applied in space programs have been rigorous and expensive. Also due to vastly-unknown nature of space environment, only few highly-qualified technologies have flown on space missions. Today, however, by the means of methods developed and/or established in the last two decades such as "qualification by similarity","Configuration control" and so on, much more responsive and cheaper qualification programs are available. Although these programs are not as precise as their predecessors, they still provide the required insight and confidence level required in most microsatellite programs. Also, due to the courageous microsatellite missions within the past, more components have been "space-qualified". At this step, the author would like to draw the readers' attention to the very point that, traditionally, there has been a considerable delay-gap in the technology-level utilized in space technology in comparison with commercial units available in the every-day market. As an example, in a microsatellite program, it is the ultimate wish of a Command and Data Handling (C\&DH) designer to be able to incorporate a computer unit with equal capabilities as of a homebased Pentium-5. This delay-gap, however, is shrinking due to the recent missions accomplished mostly by top-class universities in US, Europe, Asia and Africa [Kitts \& Lu, 1994]; [D.C.Maessen et al., 2008]; [Sabirin \& Othman, 2007]; [Triharjanto et al., 2004 ]; [Kitts \& Twiggs, 1994]; [Annes et al., 2002]. As a consequence, the technology-level of components employed in microsatellite technology is reaching that of hi-tech commercial market. Having considered the 10-20 years delay-gap of the space-qualified components and hi-tech COTS technologies, the importance of the new approach may be better understood.

As a conclusion, Table 1 compares the system-level capabilities of microsatellites in the past and at the present/near-future.

\section{System and subsystem performance requirements}

In this section, current status and future trends of various subsystems of microsatellites are discussed. Also, mutual effects of foreseen improvements of each subsystem on system performance are studied.

\subsection{Payload mass ratio to total satellite mass}

A satellite payload is the main reason to launch the whole vehicle. Thus, from a top level point of view, the more ratio of payload mass to total satellite mass (PM/TSM), the better. In the first years of microsatellite re-appearance, limited PM/TSM was practically achievable. Today, however, with the ever-increasing progress in microsatellite technology, PM/TSM as high as $10-25 \%$ is achievable, at the present and in near future, respectively. Furthermore, at the present, more capable payloads are being developed and supplied at reasonable prices, in a non-military, non-governmental market. Thus, for a given PM/TSM, currently-available 


\begin{tabular}{|c|c|c|}
\hline & capabilities in the past & $\begin{array}{l}\text { capabilities at the present and } \\
\text { near future }\end{array}$ \\
\hline $\begin{array}{l}\text { Payload mass ratio to } \\
\text { total satellite mass } \\
\text { (PM/TSM) }\end{array}$ & $5-10 \%$ & $\begin{array}{l}10-25 \% \text { at present and near } \\
\text { future }\end{array}$ \\
\hline $\begin{array}{l}\text { In-orbit autonomy (self- } \\
\text { containment of the } \\
\text { satellite) }\end{array}$ & Very poor performance & $\begin{array}{l}\text { Moderate- rapid advancement } \\
\text { expected in near future }\end{array}$ \\
\hline $\begin{array}{l}\text { Attitude knowledge and } \\
\text { control }\end{array}$ & Less than $10 \mathrm{deg}$ & Better than 1 deg at present \\
\hline $\begin{array}{l}\text { Attitude } \\
\text { maneuverability }\end{array}$ & None-Very limited & $\begin{array}{l}\text { Satisfactory- rapid } \\
\text { advancement expected in near } \\
\text { future }\end{array}$ \\
\hline $\begin{array}{l}\text { Resolution (in remote- } \\
\text { sensing systems) }\end{array}$ & $\begin{array}{l}\text { Tens of meters to a few hundreds } \\
\text { of meters }\end{array}$ & $\begin{array}{l}\text { Less than } 10 \text { meters feasible at } \\
\text { present }\end{array}$ \\
\hline $\begin{array}{l}\text { Onboard available } \\
\text { power }\end{array}$ & $\begin{array}{l}\text { Less than } 70 \mathrm{~W} \text {, thus excluding } \\
\text { power-hungry applications }\end{array}$ & $\begin{array}{l}100-200 \mathrm{~W} \text {, advancement } \\
\text { expected in near future }\end{array}$ \\
\hline $\begin{array}{l}\text { Computer (Hardware } \\
\text { and software) }\end{array}$ & Very limited & $\begin{array}{l}\text { Fairly satisfactory for current } \\
\text { applications- rapid } \\
\text { advancement expected in near } \\
\text { future }\end{array}$ \\
\hline $\begin{array}{l}\text { Communication } \\
\text { architecture }\end{array}$ & $\begin{array}{l}\text { Mostly limited to UHF/VHF/L/S- } \\
\text { Band - Low bit rates typically less } \\
\text { than } 1 \mathrm{Mbit} / \mathrm{sec}\end{array}$ & $\begin{array}{l}\text { High bit rates up to } 10 \mathrm{Mbit} / \mathrm{sec} \\
\text { at various frequencies }\end{array}$ \\
\hline Propulsion & None & $\begin{array}{l}\text { Very limited-practical } \\
\text { applications not foreseen in } \\
\text { near future }\end{array}$ \\
\hline Thermal control & Conventional applications feasible & $\begin{array}{l}\text { Conventional, more demanding } \\
\text { applications feasible - Special } \\
\text { applications such as cryogenic } \\
\text { missions not foreseen in the } \\
\text { few next years }\end{array}$ \\
\hline
\end{tabular}

Table 1. System-level capabilities of microsatellites in the past and at the present/near-future

payloads offer several-times better performance in comparison with their predecessors. Having considered the combined effect of the two preceding considerations, one may appreciate the potential applicability and ever-increasing interest of various communities in microsatellite technology. As an instance, Surrey Satellite Technology Ltd (SSTL) provides light-weight optical, navigation and communications payloads at exceptionally low prices [SSTL website, as of 2009]. A few of these capable payloads will be introduced in the following paragraphs.

\subsection{Microsatellite in-orbit autonomy}

Highly-autonomous satellites are defined as those vehicles requiring minimum contact with external sources (Terrestrial and/or Spaceborne) to successfully accomplish their intended missions [H.Bonyan, 2007]. Most microsatellites are placed in LEOs, and communications gaps (time-intervals with no contact opportunity) are inherent characteristics of LEOs. Thus, logically, a given level of in-orbit autonomy must be accommodated within the orbiting vehicle to perform mission-specific tasks, when out of ground station visibility. Accommodation of a given level of onboard autonomy is a sophisticated systems engineering activity confined by inherent mass-/power-budget constraints of microsatellite missions and also by LEO characteristics. For a microsatellite mission, once in orbit, it is 
required to autonomously perform various self-management and mission-specific tasks, to be utilized efficiently.

To some extent, autonomy issues of microsatellites have been ignored during the last decades. Consequently, there is little literature available on the preceding issues. However, rapid advancement is foreseen in near future. For further studies, the interested reader is referred to [Farmer \& R.Culver, 1995]; [A.Kitts, 1996]; [A.Swartwout \& A.Kitts, 1996]; [A.Kitts \& A.Swartwout, 1997]; [E. Vicente-Vivas, 2005]; [H.Bonyan, 2007]; [H.Bonyan \& A.R. Toloei, 2009].

\subsection{Attitude knowledge and control}

Accurate attitude knowledge and control is a crucial requirement for most practical satellites. For most remote sensing applications, one of the most promising microsatellite applications from a financial-benefit point of view, highly-accurate Attitude Determination and Control Subsystem (ADCS) is required. Lack of accurate three-axis, stabilized control capability has been a challenging obstacle in economical profitability of microsatellites. However, with microsatellites like LAPAN-TUBSAT and a few others already in orbit and many others on their way to orbit, this obstacle is already a part of history ${ }^{2}$. Today, threeaxis control with accuracies better than 1 degree are viable within microsatellite stringent monetary and mass/power/volume-budgets. Higher accuracies i.e. arc-min or better, are not foreseen in the near future. A few of the SSTL and Sun Space and Information Systems (Pty) Ltd. (Sun Space) attitude sensors and actuators are given below.

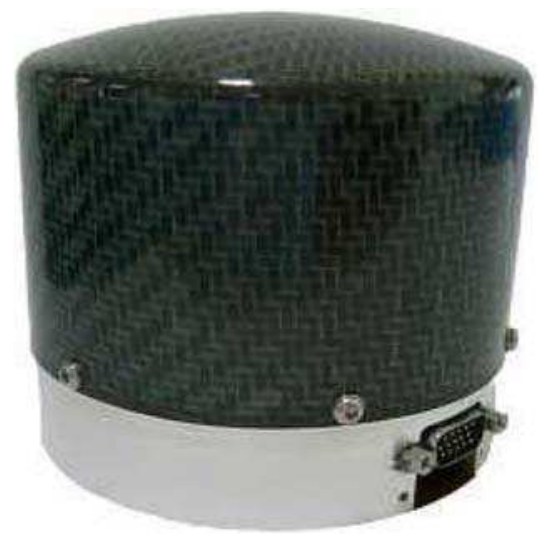

(a)

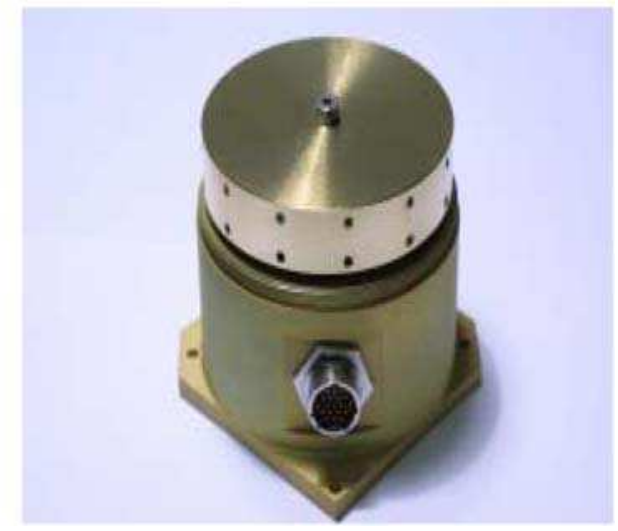

(b)

Fig. 1. SSTL lightweight, yet capable Microwheel 10SP-M, for three-axis control systems (a) and Sun Space reaction wheel with built-in electronics (b)

2 Lack of reliable three-axes ADCS has been a major reason regarding inefficient powergeneration capability of microsatellites [Bonyan \& Toloei, 2009]. With this problem already removed, 2-3 times enhancement is foreseen in power generation capability of microsatellites. 


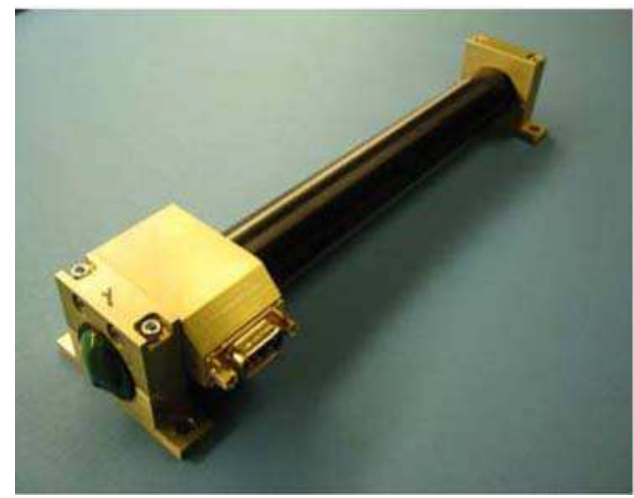

(a)

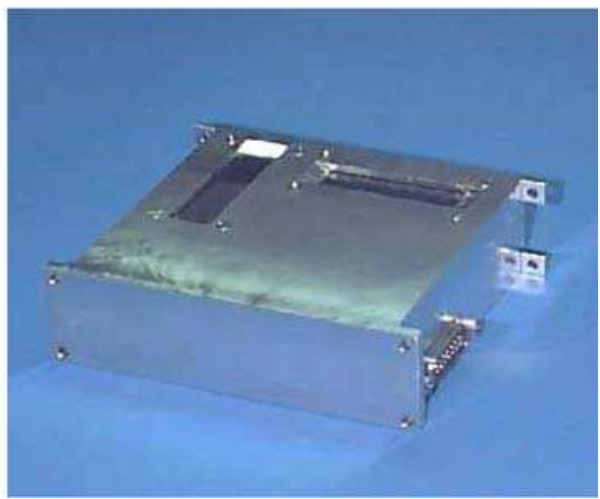

(b)

Fig. 2. The MTR-5, one of three magnetic torque rods available from SSTL (a) and SSTL 2axis DMC sun sensor (b)

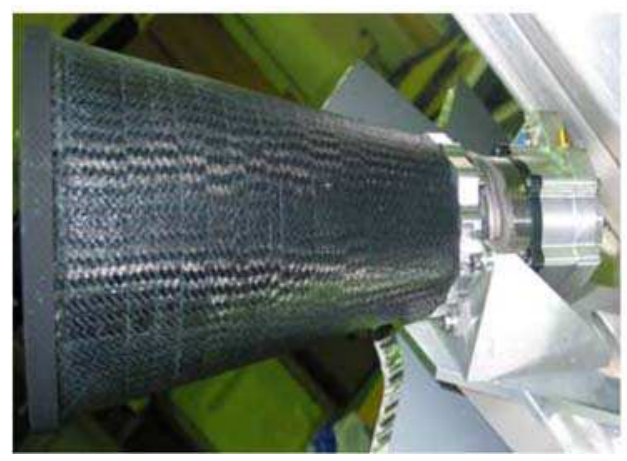

(a)

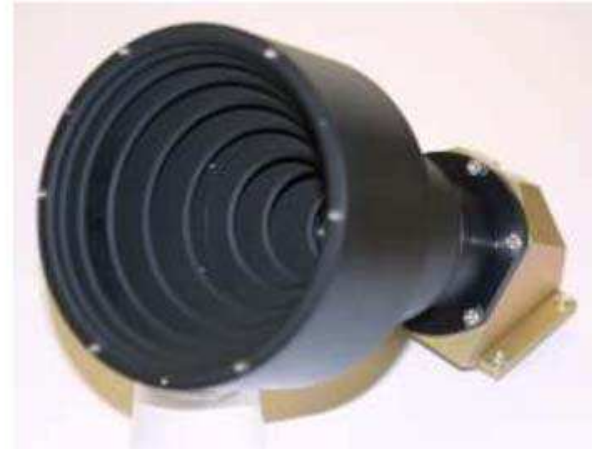

(b)

Fig. 3. SSTL star tracker (a) and Sun Space star tracker (b), both space-qualified

\subsection{Attitude manoeuvrability}

In our terminology, hereafter, attitude manoeuvrability is defined as the ability and agility of the vehicle to align itself into a new desired orientation. Attitude manoeuvrability has been traditionally one of the most demanding and challenging in-orbit activities, possible only in complicated several-hundred kilogram satellites. However, recently, microsatellites have proved their capability to accomplish demanding missions performing sophisticated Attitude manoeuvres. Thus, now, microsatellites can be scheduled to "look" into a certain direction, when over a desired location. This capability gives the operators much more flexibility to answer a user's requests in a more rapid and responsive fashion [Triharjanto et al., 2004]. With this in mind, another strategic shortcoming of microsatellite applications has been removed. 


\subsection{Resolution (in remote-sensing systems)}

Remote sensing applications are among the most promising applications of LEO microsatellites ${ }^{3}$. The main requirement of such systems comes in the form of spatial resolution or GSD (Ground Sample Distance). Most practical, financially-valuable applications require GSDs on the order of (or better than) tens of meters ${ }^{4}$, previously viable only by large satellites. Today, and/or in near future, remote sensing applications requiring resolutions as good as 5-10 meters, with frequent revisit times from a few days to a few weeks (Agriculture, Disaster monitoring, Urban planning; water resource managements, off-shore activities monitoring, to name only a few) are well within microsatellite capabilities 5 [T.Bretschneider, 2003]; [U.Renner \& M.Buhl, 2008].

\subsection{Onboard available power}

The general progress within all engineering fields holds true for electrical power subsystem of microsatellites, as well. Nowadays, more efficient power generation, storage and distribution hardware and software are available within the commercial space market. Thus, generally speaking, recent microsatellites are more capable compared to their predecessors, from an electrical power subsystem point of view. As an example, The SSTL high-efficiency $(19.6 \%)$ and very-high-efficiency solar panel and solar cell assembly is shown in fig 4 .

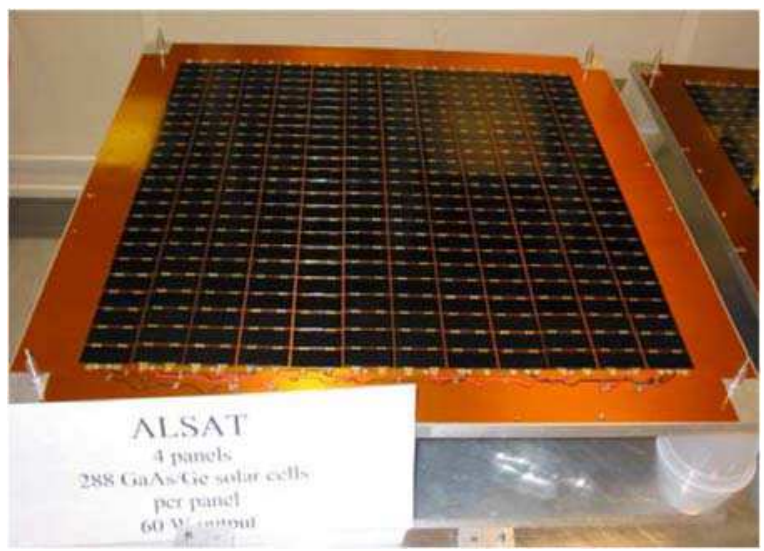

Fig. 4. SSTL solar panel and solar cell assembly

${ }^{3}$ LEO is the main domain of microsatellite missions. This has been due to low launch costs and limited capabilities of microsatellites. Although essential progress is foreseen in microsatellite technology, it is being anticipated that LEO will still serve as the main domain of microsatellite missions, due to its favourable characteristics.

4 There are certain financially-valuable applications which require GSDs on the order of tens to hundreds of meters. Thus, the typical milestones are given for a basis of comparison and better understanding of current status and future trends.

${ }^{5}$ It must be reminded that low data rates has been an off-putting drawback in microsatellite applications. Generally speaking, whatever mission-data obtained onboard the spaceborne vehicle must be transmitted to earth with reasonable time-delay to be financially-valuable. Non-real-time communication applications, yet Mbit-order data rates are now affordable within stingy mass-power- budget of microsatellite missions. 
However, Most microsatellite missions, even in recent years, have been confined to some lowpower applications [United Nations UNISPACE III, 1998]; [Bonyan, 2007]. This is, in turn, due to nature of microsatellite missions, and highly-inefficient, in-orbit configuration of microsatellites i.e. a cube with solar cells attached to external facets. A study by the same author in 2009 proved the inefficient conventional in-orbit configuration of microsatellite missions, in terms of power generation, indicating that available power level of most microsatellite missions has been as low as 50-70 watts or less. There, however, are evidences that in near future power level may be enhanced by a factor of 2-3. Thus, applications such as high data-rate communications and/or sophisticated imaging techniques in various frequency bands are well within capabilities of current and near future microsatellite missions, from a power-consumption point of view. The interested reader is referred to a study by the same author, in 2009, dealing with the subject in more detail [H.Bonyan \& A.R.Toloei, 2009].

\subsection{Command and Data Handling (C\&DH)}

Computer capability has been very limited in microsatellite technology. This has been partially due to the painstaking qualification process inherent in space projects, dominant in the previous century. Thus, although Personal Computer (PC) technology has experienced astonishing advancements in the last two decades, there still remains much effort to accommodate the already-available technology level into microsatellite missions. Fortunately, there are evidences of rapid progress within the field. This is mainly due to:

- Courageous hi-tech microsatellite missions accommodating more capable computer hardware components, thus space-qualifying "hi-tech" items

- A more-relaxed power-budget allocation for the C\&DH subsystem

- Better understanding of space environment and maturation of software programs

- New less-demanding qualification processes established,

- Introduction of various non-governmental organizations providing hi-tech computer hardware and software items,

For further detail, see [SSTL website, as of 2009]; [PHYTEC website, as of 2009]; [Freescale semiconductor website, as of 2009]; [A.Sierra et al., 2004]; [A.Woodroffe \& P.Madle, 2004]; [R.Amini et al., 2006].

The SSTL general-purpose Intel 386-based C\&DH unit and phyCORE-MCF5485 SOM Module from PHYTEC are shown in fig. 5.

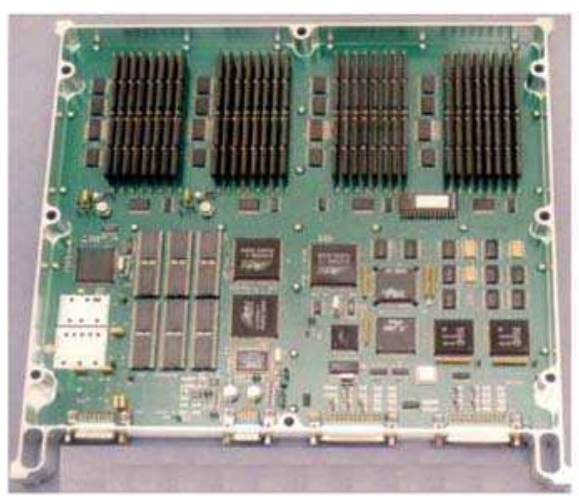

(a)

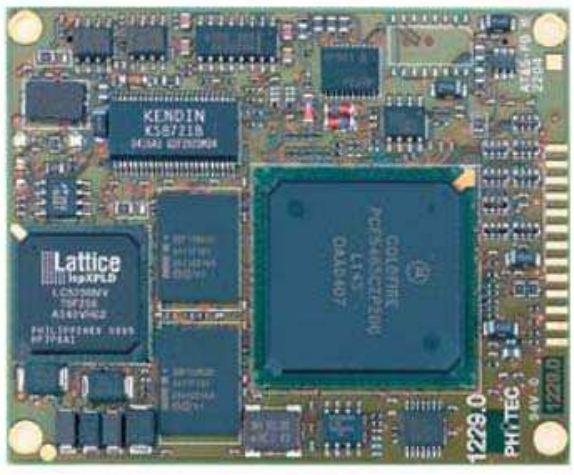

(b)

Fig. 5. SSTL OBC 386 (a) and phyCORE-MCF5485 SOM Module from PHYTEC (b) 


\subsection{Communications architecture}

Generally speaking, whatever mission-data gained onboard the satellite, must be transferred to earth for further added economical-value. This can be interpreted as a requirement of high data-rate communications systems. Previous microsatellite missions have suffered much from lack of such systems. Today, and in near future, there will be order-ofmagnitude improvements in such systems. This is mainly due to the following points:

- Communications systems, specifically those onboard the microsatellite, have considerably matured by thorough understandings provided by previous microsatellite missions. Also, ground-station technology regarding microsatellite applications has greatly advanced during the last few decades. At the present time, affordable ground station may be established at fairly-short time intervals, providing communications in various frequency bands [F.B.Hsiao et al., 2000]. Also, having fully comprehended the necessity of international cooperation and mutual benefits for all contributors, the number of joint projects in which several ground-stations are employed for a given microsatellite missions is greatly increasing [A.Kitts \& A.Swartwout, 1998 ]; [R.H.Triharjanto et al., 2004]; [D.C.Maessen et al., 2008], [Hasbi et al., 2007]; [D.C.Maessen et al., 2009]. This issue has been studied by the same author in 2007 and 2009, [H.Bonyan, 2007]; [H.Bonyan \& A.R.Toloei, 2009].

- A crucial pre-requisite of high data-rate communications is provision of a required level of electrical power. In microsatellite applications, it has rarely been possible to provide enough power to accommodate the power-hungry hardware required for such purposes. However, as mentioned previously, there is going to be a several-times enhancement in onboard available power of microsatellites. This can be interpreted as provision of much more electrical power to be fed into communications hardware, thus much higher data-rates.

SSTL S-band communications hardware is shown in fig. 6.

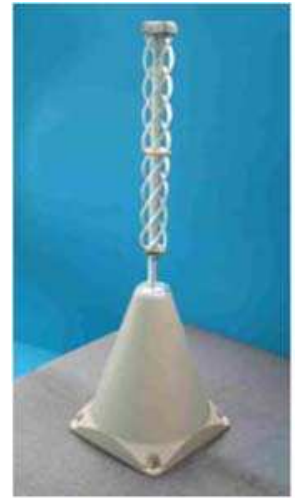

(a)

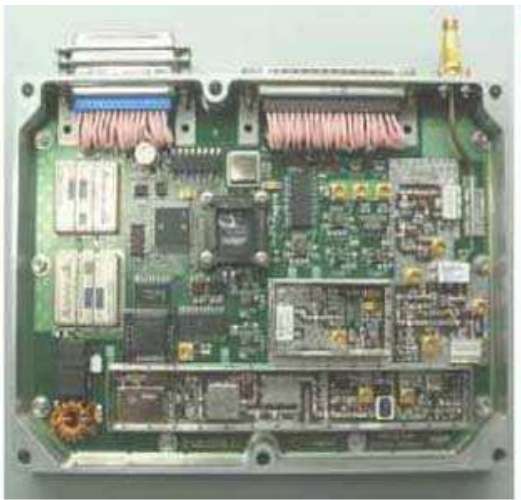

(b)

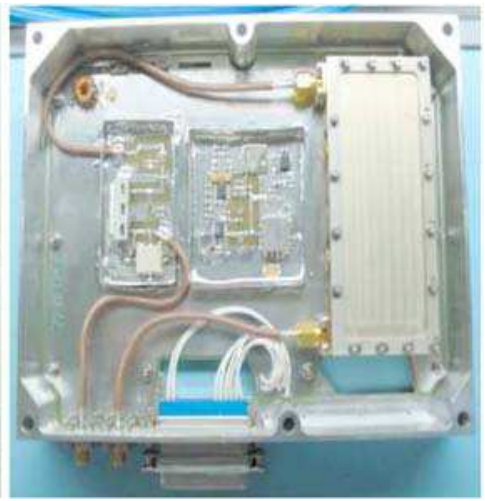

(c)

Fig. 6. SSTL S-Band Quadrifilar Helix Antenna (a), S-Band transmitter (b) and S-band receiver down-converter module (c)

\subsection{Propulsion}

Historically, microsatellites have not been equipped with propulsion systems. Although there have been experiences of carrying propulsion systems onboard microsatellites, these 
experiences have been mainly for technology-demonstration and space-qualification purposes. Realistically, practical applications of onboard propulsion systems for microsatellites are not foreseen in near future. However, it must be reminded that lack of propulsion system does not sully unique features of microsatellite technology. By some rough calculations, microsatellites placed in orbits with altitudes higher than $700-800 \mathrm{~km}$ will maintain their orbit with sufficient accuracy for periods of up to 5-10 years, well covering lifetime of most microsatellite missions, typically 3-5 years ${ }^{6}$. Some SSTL propulsion hardware, adequate for microsatellite missions, is shown in fig. 7.

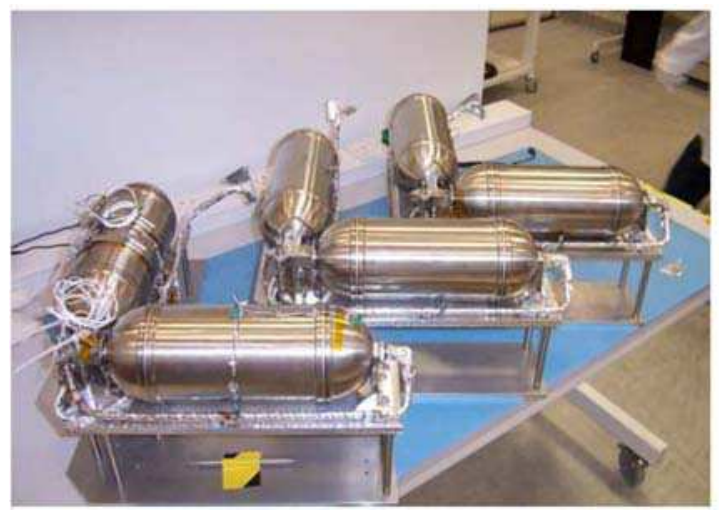

(a)

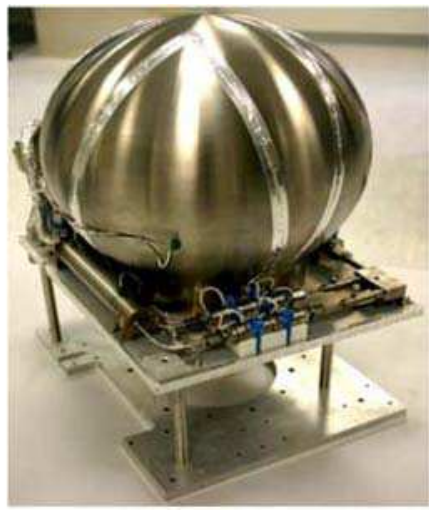

(b)

Fig. 7. SSTL microsatellite Butane propulsion system (a) and SSTL Xenon Propulsion System

\subsection{Thermal control}

It is the ultimate goal of thermal-control designers to passively meet the thermal requirements of a satellite. In case of conventional applications of microsatellites, passive and/or semi-active thermal control systems have proved to be more than adequate. On the contrary, accommodating specific payloads, such as cryogenic ones which impose severe thermal requirements, are not foreseen in the next few years. However, in near future, such systems may be accommodated within courageous microsatellite missions, if economicallyjustified.

\section{Construction}

Compared to the first days of space age, there have been general enhancements in construction techniques of all aerospace vehicles, and microsatellites are not exceptions. For

\footnotetext{
6 The Dutch TU Delft and Chinese Tsinghua University are planning an ambitious formation flying mission, to be launched by the end of 2011. During the 2.5-year mission, the two satellites, FAST-D (being developed in Delft) and FAST-T (being developed in Beijing), will demonstrate various new technologies such as autonomous formation flying with distributed propulsion systems and MEMS technology to optimize propellant consumption. This mission, if successful, can effectively propose "propulsion subsystem" as a feasible feature onboard microsatellites.
} 
most aeronautical applications, national and/or international organizational construction facilities have been established in order to provide the required services and to simultaneously reduce construction costs of each individual project. This holds partially true for large space projects, as well. However, in case of microsatellites, such national/international facilities have just been or are being established. Thus, once fully deployed, these facilities may reduce construction costs of microsatellite projects, considerably. Also, with the increasing demand for microsatellite-suited applications, there will be more investment for such facilities, nationally and internationally. Having considered the two preceding issues and increasing number of such facilities and services supplied at each facility, it is being concluded that construction of microsatellites will be faster and more affordable in near future.

A few of these construction-facilities/suppliers are listed in Table 2.

\section{Test}

Test philosophies, in space applications, have been always rigorous, time-consuming and expensive. Qualification/Acceptance tests usually impose too conservative constraints on space applications. However, with the experiences gained during the several decades of space age, there seems to be a trend toward less demanding test procedures. Therefore, the "sacred" test programs which were more than mandatory for all space programs are now simply "Negotiable". It must be reminded that there exists a fragile difference between "negotiable requirements" and simply ignoring the handy qualification tools developed through many years and at the cost of many lives and dollars.

As already mentioned, during the 60s-90s, test programs were more than demanding. Any space project had to go through various time-consuming and very expensive test programs to acquire the launch "go-ahead". This was mainly due to:

- $\quad$ Lack or uncertainty in knowledge of space environment

- Extensive uncertainty and immaturity in analysis software

- Lack of software-in-the-loop simulation techniques

- Astronomical financial budgets supplied by the governments

- Lack of self-confidence within the space community in their products (more and more tests were desired to see if it "really works")

Today, however, due to the experience gained in previous years, with the help of software packages available at very low costs and confidence developed within space community and due to shortage in financial resources, less demanding, yet consistent, test programs have been established.

\section{Launch}

Not exaggerated, launch is what makes the space expensive. According to [H.Bonyan, 2008], launch cost can make up to $50 \%$ of the whole project cost. To be truly capable of analyzing the expensive launch phase, a brief history of the issue must be presented:

What is today known as space launch began in 1957, by the Soviet Union. However, the first engineering efforts may be traced back to the second world war (WW II), in which, the German army successfully developed the first ballistic missile i.e. the V2. After the WW II, the soviets and Americans both made all their effort to acquire the German ballistic missile technology. The Americans were the first to arrive and they got the chief designer Werner 


\begin{tabular}{|c|c|c|}
\hline & Country & Products/Services \\
\hline $\begin{array}{l}\text { Actel } \\
\text { Corporation }\end{array}$ & US & $\begin{array}{l}\text { field programmable gate arrays (FPGAs) based on anti-fuse and } \\
\text { flash technologies and embedded programmable gate arrays } \\
\text { (EPGAs) based on SRAM technology, as well as high-performance } \\
\text { intellectual property (IP) cores, software development tools and } \\
\text { design services }\end{array}$ \\
\hline AeroAstro Inc & US & $\begin{array}{l}\text { Radios, Imagers, star trackers, sun sensors, communications hardware, } \\
\text { etc }\end{array}$ \\
\hline $\begin{array}{l}\text { Atmel Wireless } \\
\& \\
\text { Microcontrollers }\end{array}$ & $\begin{array}{c}\text { US/ } \\
\text { International }\end{array}$ & space qualified ICs \\
\hline $\begin{array}{l}\text { Carlo Gavazzi } \\
\text { Space (CGS) }\end{array}$ & Italy & $\begin{array}{l}\text { ISS utilization, instrumentation and processors for scientific and } \\
\text { application payloads, instruments for microgravity experiments, small } \\
\text { satellites, attitude control and modeling, mission analysis, on-board } \\
\text { automation }\end{array}$ \\
\hline CSEM & Switzerland & $\begin{array}{l}\text { systems engineering and design, mechanical engineering, wavefront } \\
\text { engineering, micro-imagers, robotic systems, optical systems for high } \\
\text { accuracy pointing, smart structures for artificial damping of vibrations, } \\
\text { micro/nano technologies for small satellites }\end{array}$ \\
\hline Fokker Elmo & $\begin{array}{l}\text { Netherlands/ } \\
\text { International }\end{array}$ & $\begin{array}{l}\text { wiring harnesses, magnetic torque rods, printed circuit boards, multi } \\
\text { layer insulation }\end{array}$ \\
\hline Honeywell Inc & $\begin{array}{c}\text { US/ } \\
\text { International }\end{array}$ & $\begin{array}{l}\text { guidance, navigation and control systems for launch vehicles and } \\
\text { spacecraft; data handling management and processing systems; space } \\
\text { instrumentation and sensors; on board data processors; display systems; } \\
\text { flight and engine controls for manned space flight; satellite mechanisms; } \\
\text { precision inertial instruments; radiation hardened memories; re-entry } \\
\text { vehicles; reaction wheel assemblies; antenna pointing systems }\end{array}$ \\
\hline $\begin{array}{l}\text { Matra Marconi } \\
\text { Space }\end{array}$ & International & $\begin{array}{l}\text { communications, earth observation and scientific satellites; structures } \\
\text { and mechanisms; attitude and orbit control systems; robotics; optical } \\
\text { communications; propulsion systems; sterling cycle cryogenic coolers; } \\
\text { on board data handling; antennas; optics; sensors; power systems; } \\
\text { microwave and millimetre wave components; hardened ASICs; } \\
\text { radiometers }\end{array}$ \\
\hline Megsat & Italy & $\begin{array}{l}\text { microsatellite subsystems; high efficiency solar arrays; power } \\
\text { subsystems; mechanical devices; actuators; antennas for microsatellites }\end{array}$ \\
\hline SpaceDev Inc & US & $\begin{array}{l}\text { design, manufacture, marketing and operation of sophisticated micro and } \\
\text { nano satellites, hybrid rocket-based orbital Maneuvering and orbital } \\
\text { Transfer Vehicles (MTVs) as well as safe sub-orbital and orbital hybrid } \\
\text { rocket-based propulsion systems; commercial hybrid rocket motors and } \\
\text { small high performance space vehicles and subsystems }\end{array}$ \\
\hline Spectrum Astro & USA & $\begin{array}{l}\text { small spacecraft buses, space electronics and power management } \\
\text { systems, electrical ground support and ground control equipment }\end{array}$ \\
\hline $\begin{array}{l}\text { SunSpace \& } \\
\text { Information } \\
\text { Systems }\end{array}$ & South Africa & high performance micro-satellites and imagers \\
\hline SSTL & UK & manufacturer of mini and microsatellites \\
\hline $\begin{array}{l}\text { Swedish Space } \\
\text { Corporation } \\
\text { (SSC) }\end{array}$ & Sweden & $\begin{array}{l}\text { system integrator and supplier of small and micro-satellites; develops } \\
\text { attitude orbit \& control systems, onboard data handling units, software, } \\
\text { propulsion systems and ground systems for testing and mission control; } \\
\text { extensive operational experience }\end{array}$ \\
\hline
\end{tabular}

Table 2. some construction-facilities/suppliers in various countries ${ }^{7}$

7 This table is not intended to provide a complete list of construction-facilities/suppliers and is only meant to name a few. A comprehensive list can be found at EPPL (European Preferred Part List ), Issue 13; Issue Date: 2008-09-12 
Von Braun with his most outstanding men. Von Braun was secretly sent to US and was soon the most influential designer in the US ballistic missile program. The soviets, on the other hand, got most of the technicians and the hardware and soon moved them to the soviet territories. The reader's attention is drawn to the point that the US had already acquired the atomic-bomb (A-bomb) technology during the WW II, under the project named The Manhattan Project in which they tested an A-bomb in the US remote territories and dropped two on the Japanese cities. The soviets, thanks to their covert intelligence network within the US territory, had their hands on the A-bomb technology as soon as a year after the WW II. Thus, with the A-bomb technology available, both nations looked for the necessary deliverymeans to launch their A-bombs over great distances. The necessity for the delivery-system for A-bombs was the main driver for the InterContinental Ballistic Missile (ICBM) programs, in both east and west. The soviets, however, made much more effort due the fact that they had almost no means of A-bomb delivery to the US territory while the US had its A-bombequipped aircrafts in several Air-Force-Bases (AFB) located in lands near to or neighbouring the soviet territory ${ }^{8}$. Thus the soviets made all their effort to counterbalance the condition and in 1957, the efforts came to reality. They, however, picked up a much more dramatic approach to prove their ICBM capability. Since a ballistic missile has much in common with a LEO launch vehicle, the soviets placed the first man-made satellite Sputnik-1 to prove their ICBM capability, in 1957. Spunik-1 and R-7, the first ICBM/launch-vehicle in the world, are shown in figure 8 .

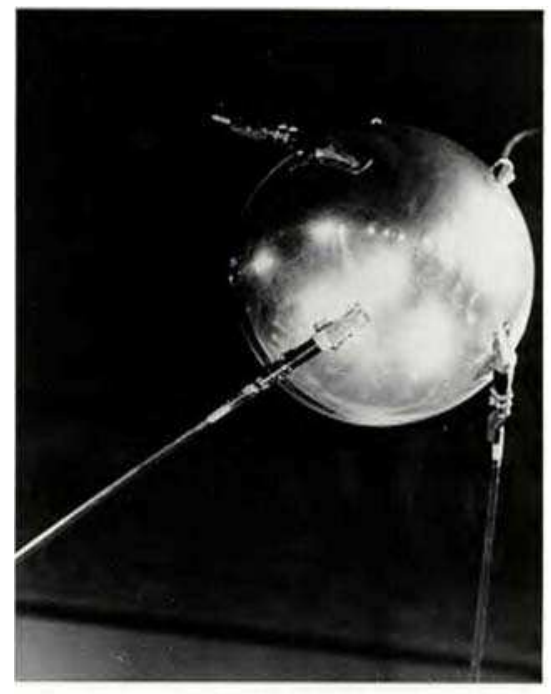

(a)

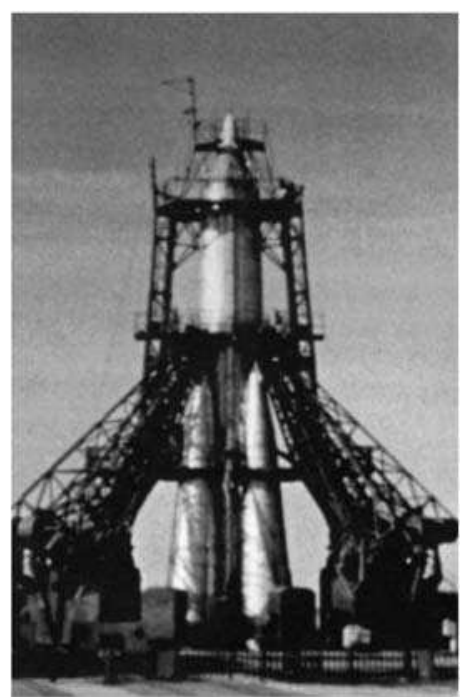

(b)

Fig. 8. First artificial satellite Sputnik-1 (a) and soviet R-7 launch vehicle with Sputnik 2 as its payload (b)

8 This, in turn, was because of due-east policy of the NATO (North Atlantic Treaty Organization), during the cold war. US, by the first years of 1960's, had its NATO AFBs in several European countries, near to or neighbouring the soviet union. 
During the first two decades after the first space flight, Launch-campaign was an issue mainly influenced by the political and military drivers. From 1980s and afterwards, specifically after collapse of the Soviet Union, cost has been considered as the main parameter in space launch community. In 1990s and after the Cold War, LEO launch was as expensive as 30,000 US \$/Kg which was still quite high for many nations and organizations ${ }^{9}$. The following table summarizes launch cost per pound (kilogram) for different small launch vehicles (5,000 lbs. or less to LEO), as of 1990-2000.

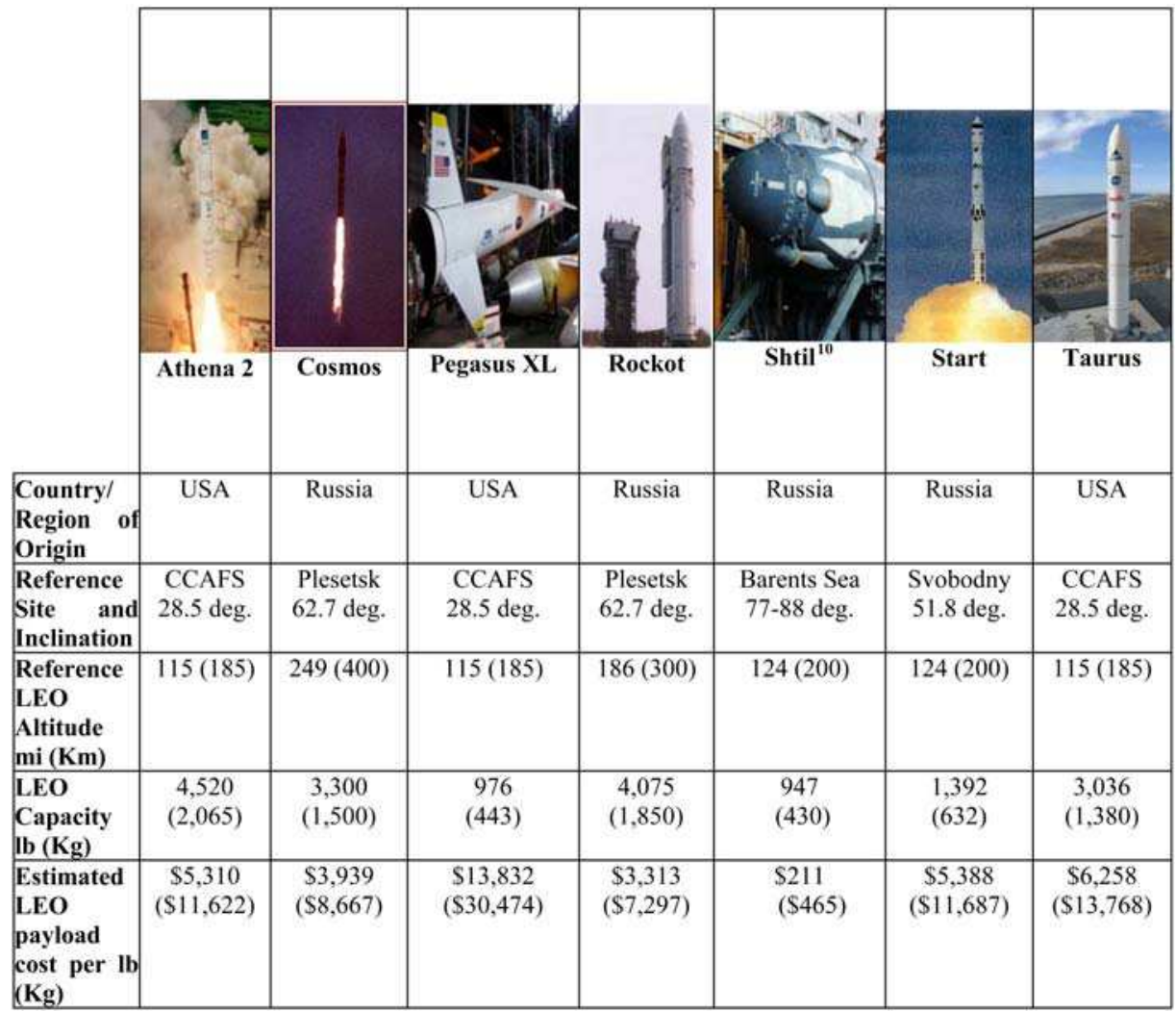

Table 3. Launch cost per kilogram for different Small (5,000 lbs. or less to LEO) launch vehicles, as of 1990-2000

At this moment, it must be reminded that after collapse of the Soviet Union, there has been a general tendency within the Russian space sector to utilize the inherited, already-available InterContinental Ballistic Missile (ICBM) infrastructure for commercial space launches in order to raise extra funding for space activities and partially avoid high maintenance costs

9 This is, in turn, one of the main reasons why microsatellites have gained more and more attention during the last 2-3 decades. Microsatellites are obviously much cheaper and quite affordable to be launched into orbit, compared to conventional large satellites.

10 Shtil launch costs are partially subsidized by the Russian Navy as part of missile launch exercises 
of such systems. These new launchers, also known as converted-ICBMs, offer inexpensive and frequent launch opportunities to various space communities. It is being anticipated that in the next decade, there will be frequent and affordable launch opportunities provided by the Russian space-launch market. The following derivatives of the soviet ICBMs now serve as launch vehicles:

1. Rockot (Based on SS-19 ICBM; flight proven more than 140 times)

2. Shtil (a derivative from R-29-family of submarine-launched ballistic missiles)

3. Dnepr ( based on RS-20 ICBM; SS-18 Satan by NATO designation)

4. Start (based on RT-2PM Topol, NATO reporting name: RS-12M Topol ICBM)

5. Strela (based on UR-100 ICBM, NATO reporting name SS-11 Sego)

6. Tsyklon (based on R-36 ICBM, NATO reporting name SS-9 Scarp)

7. Volna (based on R-29R submarine-launched ballistic missiles)

Current Status and Future Trends of Russian Space-Launch Market is being addressed by the same author in a separate paper [M.Malekan \& H.Bonyan, 2010].

Table 4 summarizes launch cost per pound (kilogram) for different medium $(5,001-12,000$ lbs. to LEO) and intermediate (12,001-25,000 lbs. to LEO) launch vehicles, as of 1990-2000.

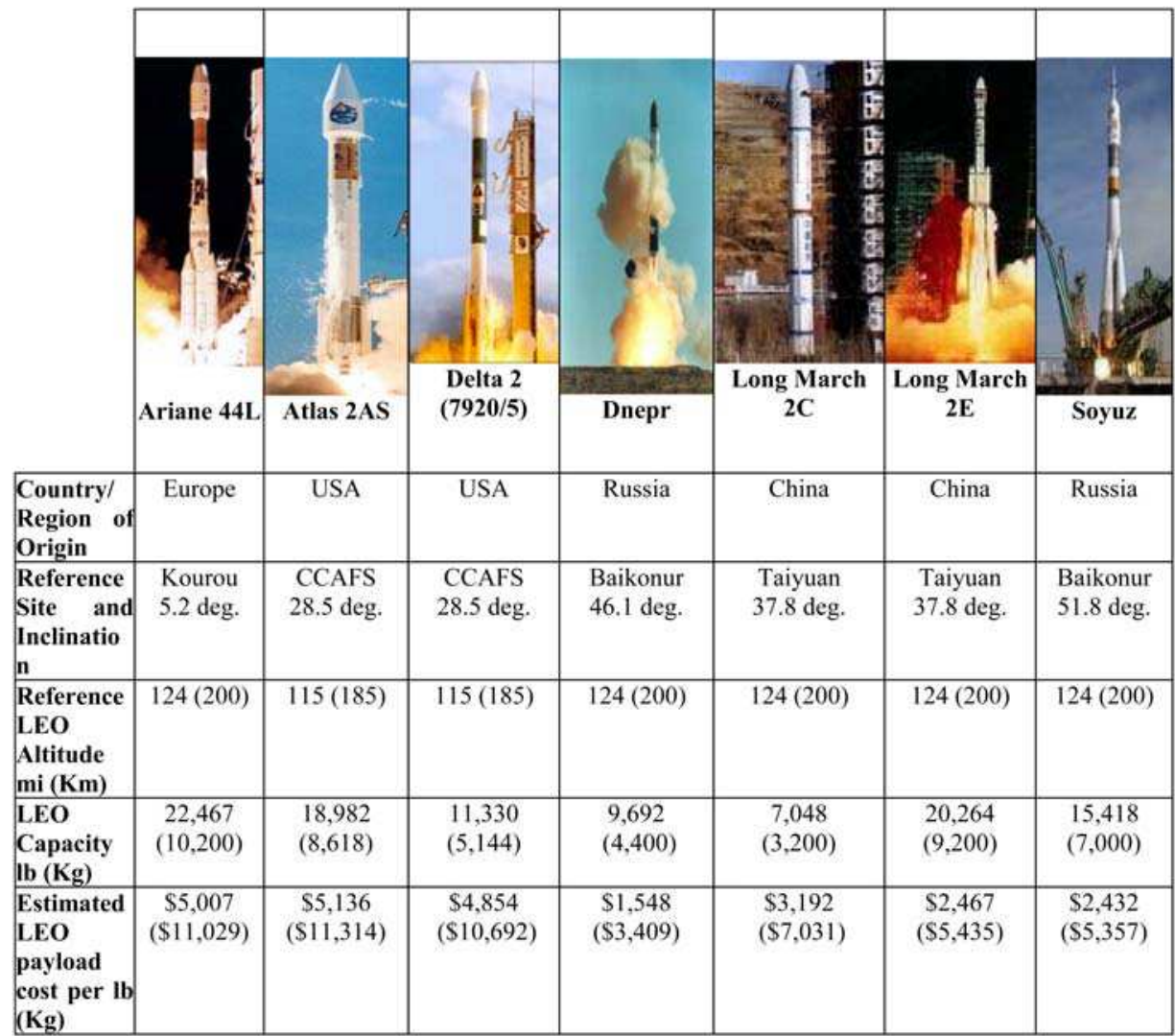

Table 4. Launch cost per kilogram for different medium (5,001-12,000 lbs. to LEO) and intermediate (12,001-25,000 lbs. to LEO) launch vehicles, as of 1990-2000 
Finally, Launch cost per kilogram for different heavy (more than 25,000 lbs. to LEO) launch vehicles is shown in table 5, as of 1990-2000.

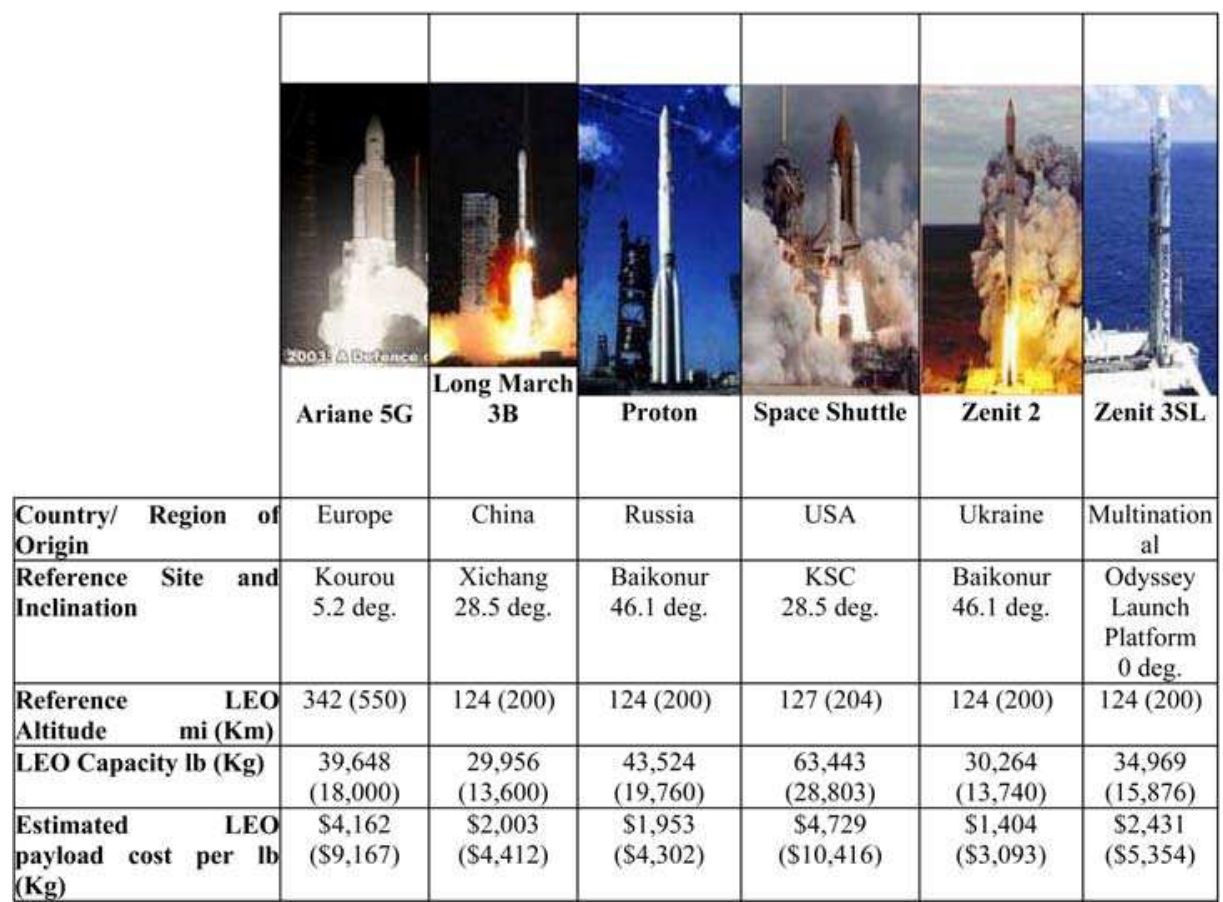

Table 5. Launch cost per kilogram for different heavy (more than 25,000 lbs. to LEO) launch vehicles, as of 1990-2000

The price-per-pound (kilogram) figures in the previous tables vary significantly from a launch vehicle to another. From the preceding tables, it is concluded that the non-western (Russian/Ukrainian, Chinese) vehicle offer lower prices than their western counterparts (American and European), primarily because of lower labour and infrastructure costs. The following table shows that these differences in average price-per-pound can be significant [Futron Corporation Manual, 2002].

\begin{tabular}{|l|c|c|}
\hline \multirow{2}{*}{ Vehicle Class } & \multicolumn{2}{|c|}{ Average Price-per-pound @ LEO (\$/lb) } \\
\cline { 2 - 3 } & Western & Non-Western \\
\hline Small & 8,445 & 3,028 \\
\hline Medium/Intermediate & 4,994 & 2,407 \\
\hline Heavy & 4,440 & 1,946 \\
\hline
\end{tabular}

Table 6. Average Price-per-pound for Western and Non-Western Launch Vehicles ${ }^{11}$, as of 1990-2000

11 The Zenit 3SL is considered a non-Western launch vehicle because of its Ukrainian and Russian heritage. 


\section{Post-launch operations}

Post-launch (in-orbit) operation of microsatellites has been vastly ignored, both in practice and in the literature, until very recently. During the last decade, however, the significance of the issue has been highlighted by various communities and is evolving rapidly [R.Annes et al., 2002], [Hardhienata et al., 2005], [H.Bonyan 2010]. There, however, still remain certain shortcomings regarding in-orbit operations of microsatellites. In fact, most involved-parties are reluctant to officially declare inefficient in-orbit utilization of their microsatellites. Without referring to any specific project, it is being highlighted that according to the author's studies, there are several cases in which fully-operational microsatellites have been almost abandoned in orbit due to poor in-orbit operations strategy. These crafts could have provided invaluable services, with considerable financial benefit, if adequate short- /longterm in-orbit operations strategy had been carefully planned. It is being reminded that in the next decades, microsatellites will not only serve as hands-on experience to train university students and to be financially-valuable, much attention must be paid to the in-orbit operations of such vehicles.

\section{Reference}

R.Amini, Gerard Aalbers, Rob Hamann, Wim Jongkind (2006), New Generations of Spacecraft Data Handling systems Less Harness more Reliability, 57th International Astronautical Congress, Valencia, Spain

Annes et al., (2002), Operation Delfi - A Space Mission Development Project, 17th AMSAT-

UK Colloquium, Guildford, Surrey, England, UK

H.Bonyan (2010). An in-depth Analysis of the Ambiguity of Economical-profitability of Microsatellite Missions, accepted for publication in IEEE Aerospace conference Big Sky, MT USA

H.Bonyan (2010), Efficient In-orbit Operations of LEO Polar/Sun-synchronous Satellites; Southern Hemisphere Revisited?, accepted for publication in IEEE Aerospace conference Big Sky, MT USA

H.Bonyan and A.R.Toloei (2009), Systems Engineering Analysis of Required Level of On-orbit Autonomous Operation of a LEO Student-microsatellite Mission, Recent Advances in Space Technology conference (RAST 2009), Istanbul, Turkey

H.Bonyan and A.R.Toloei (2009), Systems Engineering Approach toward the Problem of Sunlight Collection of a Light-micro Satellite, Recent Advances in Space Technology conference (RAST 2009), Istanbul, Turkey

H.Bonyan (2008), Investigation and Utilization oF the Low-earth Equatorial Orbits for Missions Concerning the African Continent, AIAA \& IEEE joint conference, Big Sky, USA

H.Bonyan (2007), System engineering approach toward the problem of battery depth-ofdischarge of a LEO satellite, International Conference on Complex Systems (ICCS) Quincy MA USA 
H.Bonyan (2007), Systems Engineering Approach toward the Problem of Required Level of In-orbit Autonomous-operation of a LEO Microsatellite Mission, International Conference on Complex Systems (ICCS) Quincy MA USA

T. Bretschneider, S.H. Tan, C.H. Goh, K. Arichandran, W.E. Koh, E. Gill (2003), X-SAT Mission Progress, 5th IAA Symposium on Small Satellites for Earth Observation IAA-B5-0504, Berlin, Germany

Farmer, Mike and Randy Culver (1995), The Challenges of Low-Cost, Automated Satellite Operations, Proceedings of the 31st International Telemetering Conference, Las Vegas, Nevada, pp. 203-209

Futron Corporation Manual (2002), Space Transportation Costs: Trends in Price per Pound to Orbit 1990-2000

E. Gill et al. (2008), Atmospheric Aerosol Characterisation with the Dutch-Chinese FAST Formation Flying Mission, IAC-08-B1.I.1, In Proc. of the 59th IAC, Glasgow, Scotland

G. Grillmayer et al, (2003), ILSE - First Laboratory Model of the Small Satellite Program at the University of Stuttgart 54th International Astronautical Congress, Bremen, Germany

S. Hardhienata, A. Nuryanto, R. H. Triharjanto, U. Renner (2005), Technical Aspects and Attitude Control Strategy of LAPAN-TUBSAT Micro Satellite, 5th IAA Symposium on Small Satellites for Earth Observation, Berlin, Germany

W.Hasbi, E.Nasser, A.Rahman (2007), Spacecraft Control Center of Lapan-Tubsat Micro Satellite, 3rd Asian Space Conference, NTU@one-north campus, Singapore

Fei-Bin Hsiao ,Hui-Ping Liu , Chung-Cheng Chen (2000), The Development of a Low-Cost Amateur Microsatellite Ground Station for Space Engineering Education, Global J. of Engng. Educ., Vol.4, No.1 Printed in Australia

http://www.freescale.com/webapp/sps/site/homepage.jsp?nodeId=0162468rH3 , last visited July 2009

http:// www.ic.gc.ca/app/ccc/srch/nvgt.do?lang=eng\&prtl=1\&sbPrtl=\&estblmntNo=1234 56114317\&profile $=$ cmpltPrfl\&profileId=1421\&app=sold , last visited July 2009

http://www.phytec.com/ , last visited July 2009

http://www.rockwellcollins.com/about/locations/deutschland/index.html , last visited July 2009

http://www.sstl.co.uk/ , last visited July 2009

http://www.sunspace.co.za/ , last visited July 2009

Kitts, Christopher A. and Michael A. Swartwout (1998), Experimental Initiatives in Space System Operations, In Proceedings of the Annual Satellite Command, Control and Network Management Conference, Reston, VA Presented by Kitts in the Systems and Mission Analysis Session. Also presented by Michael A. Swartwout at the 1998 INFORMS Conference, Monterey, CA, January, 1998, Spacecraft Automation Session

Kitts, Christopher A (1996)., A Global Spacecraft Control Network for Spacecraft Autonomy Research, In Proceedings of SpaceOps '96: The Fourth International Symposium on 
Space Mission Operations and Ground Data Systems, Munich, Germany. Presented by Kitts in the Operations Automation Session

Kitts, Christopher A., and Robert J. Twiggs (1994), the Satellite Quick Research Testbed (SQUIRT) Program, In Proceedings of the 8th Annual AIAA/USU Conference on Small Satellites, Logan, Utah

Kitts, Christopher A., and Richard A. Lu (1994), The Stanford SQUIRT Micro Satellite Program, In Proceedings of the AMSAT-NA 12th Space Symposium and AMSAT Annual Meeting, Orlando, Florida, Presented by Robert J. Twiggs at the 1994 AMSAT-NA Space Symposium, Orlando, Florida

Larson Wiley J., James R.Wertz (1992) Space Mission Analysis and Design, pp. 393 \& 397

Maessen D.C. et al. (2009), Mission Design of the Dutch-Chinese FAST Micro-Satellite Mission, 7th IAA Symposium on Small Satellites for Earth Observation, Berlin, Germany

Maessen D.C. et al. (2008), Preliminary Design of the Dutch-Chinese FAST Micro-Satellite Mission, In Proc. of the 4S Symposium, Rhodes, Greece

M.Malekan \& H.Bonyan (2010), On the Current Status and Future Trends of Russian SpaceLaunch Market, accepted for publication in IEEE Aerospace conference Big Sky, MT USA

U.Renner, Matthias Buhl (2008), High Precision Interactive Earth Observation with LAPANTUBSAT, Proceedings of the 4S Symposium Small Satellites, Systems and Services, Rhodos, Greece

A.Sabirin, M.Othman (2007), Razaksat- High resolution imaging satellite for near equatorial orbit (Neqo) COSPAR/IAF Symposium, "Use of the equatorial orbit for space science and applications: Challenges and opportunities", Vienna, Austria

A.Sierra, Juan J. Quiroga, Roberto Fernández and Gustavo E. Monte (2004), An Intelligent Maintenance System for Earth-based Failure Analysis and Self-repairing of Microsatellites, Acta Astronautica Volume 55, Issue 1, Pages 61-67

Swartwout, Michael A., and Christopher A. Kitts (1997), Automated Health Operations for the SAPPHIRE Spacecraft, In Proceedings of ITC/USA 196: The 33rd Annual International Telemetering Conference, Las Vegas, NV. Presented by Swartwout in the Space Systems Session

Swartwout, Michael A., and Christopher A. Kitts (1996), A Beacon Monitoring System for Automated Fault Management Operations, In Proceedings of the Tenth Annual AIAA/USU Small Satellite Conference, Logon, UT. Presented by Swartwout in the University Student Session. Honourable Mention Winner in Student Paper Competition

Third United Nations Conference on the Exploration and Peaceful Uses of Outer Space, UNISPACE III, 1998

Triharjanto, H.R., et al, (2004), LAPAN-TUBSAT: Micro-satellite platform for surveillance and remote sensing, $4 \mathrm{~S}$ symposium, Paris, France

E. Vicente-Vivas, Fabián García-Nocetti and Francisco Mendieta-Jiménez (2005), Automatic maintenance payload on board of a Mexican LEO microsatellite, Acta Astronautica Journal, Elsevier Science, Volume 58, Issue 3, Pages 149-167 
A. M. Woodroffe and P. Madle (2004), Application and experience of CAN as a low cost OBDH bus system, MAPLD 2004, Washington D.C. USA 


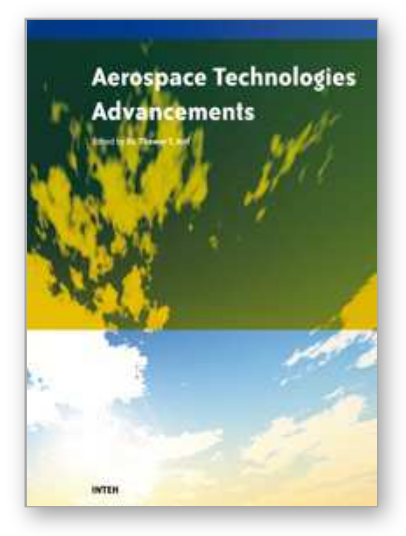

\author{
Aerospace Technologies Advancements \\ Edited by Thawar T. Arif
}

ISBN 978-953-7619-96-1

Hard cover, 492 pages

Publisher InTech

Published online 01, January, 2010

Published in print edition January, 2010

Space technology has become increasingly important after the great development and rapid progress in information and communication technology as well as the technology of space exploration. This book deals with the latest and most prominent research in space technology. The first part of the book (first six chapters) deals with the algorithms and software used in information processing, communications and control of spacecrafts. The second part (chapters 7 to 10) deals with the latest research on the space structures. The third part (chapters 11 to 14 ) deals with some of the latest applications in space. The fourth part (chapters 15 and 16) deals with small satellite technologies. The fifth part (chapters 17 to 20) deals with some of the latest applications in the field of aircrafts. The sixth part (chapters 21 to 25 ) outlines some recent research efforts in different subjects.

\title{
How to reference
}

In order to correctly reference this scholarly work, feel free to copy and paste the following:

H. Bonyan (2010). Looking into Future - Systems Engineering of Microsatellites, Aerospace Technologies Advancements, Thawar T. Arif (Ed.), ISBN: 978-953-7619-96-1, InTech, Available from: http://www.intechopen.com/books/aerospace-technologies-advancements/looking-into-future-systemsengineering-of-microsatellites

\section{INTECH}

open science | open minds

\author{
InTech Europe \\ University Campus STeP Ri \\ Slavka Krautzeka 83/A \\ 51000 Rijeka, Croatia \\ Phone: +385 (51) 770447 \\ Fax: +385 (51) 686166 \\ www.intechopen.com
}

\author{
InTech China \\ Unit 405, Office Block, Hotel Equatorial Shanghai \\ No.65, Yan An Road (West), Shanghai, 200040, China \\ 中国上海市延安西路65号上海国际贵都大饭店办公楼 405 单元 \\ Phone: +86-21-62489820 \\ Fax: +86-21-62489821
}


(C) 2010 The Author(s). Licensee IntechOpen. This chapter is distributed under the terms of the Creative Commons Attribution-NonCommercialShareAlike-3.0 License, which permits use, distribution and reproduction for non-commercial purposes, provided the original is properly cited and derivative works building on this content are distributed under the same license. 